\title{
MÉTODO ESTILÍSTICO Y POESÍA: APUNTES SOBRE JESÚS MONTIEL
}

Julio Salvador Salvador

Universidad Complutense de Madrid

https://doi.org/10.18778/8220-195-6.05

\section{Resumen}

El presente artículo tiene como objetivo poner de manifiesto la utilidad del método estilístico para el análisis de la literatura. Para ello, en primer lugar, se ofrece una breve panorámica sobre las opiniones que algunos especialistas han vertido en relación a la estilística enfatizando en algunas características de dicha metodología. En segundo lugar, se estudian poemas del poeta granadino Jesús Montiel para, a partir de las pautas de examen de la escuela alonsiana, ahondar en su poética, una de las más novedosas dentro del panorama poético español en la actualidad.

Palabras clave: análisis literario, estilística, poesía española actual, Jesús Montiel, existencialismo.

\section{1.}

\section{Introducción}

Las fricciones que en ocasiones surgen entre la tradición y la novedad ponen de relieve las dificultades metodológicas a las que se enfrentan los jóvenes especialistas en la actualidad. En el momento en el que alguien se dispone a profundizar en un tema de investigación, se le presenta un gran problema: “¿Y usted, a qué escuela pertenece?”. La filiación doctrinal que se reconoce es a las escuelas que vienen del extranjero, que con el paso de los años, 
se han convertido en un auténtico cajón de sastre: formalismo, post-estructuralismo, estudios culturales, etc.

Evidentemente, el problema no reside en que se asuman las posiciones teóricas del extranjero, sino que tal vez radique en que los nuevos estudiosos no saben con exactitud cómo estas escuelas abordan el análisis de la literatura. También resulta corriente desdeñar antiguos modelos solo por sus antecedentes socio-históricos, en una sublimación hasta el absurdo del dominio de otras metodologías. ¿Por qué no se puede abogar por un método ecléctico, por un método que englobe al resto, para obtener una perspectiva integradora, rica en matices? Hoy en día es imperativo para el investigador crear oportunidades, permitir que en esta oscilación entre tradición y novedad los estudios hispánicos apuesten por un análisis sincrético del objeto estético. Y es al llegar a este punto, cuando la estilística se erige como un faro al que dirigirse, ya que, a pesar de su idealismo heredado del subjetivismo romántico, ofrece una cohesión en cuanto al tipo de examen al que se ha de someter a un texto. Más, si la renovamos con todo el camino recorrido a lo largo de las últimas décadas por la estética de la recepción o, incluso, el materialismo cultural. Como ejemplo, este capítulo tratará de volver sobre algunas de las ideas de la estilística alonsiana y reutilizarlas para analizar a uno de los poetas más sobresalientes en España de los últimos años, Jesús Montiel.

\section{2. \\ Algunas cuestiones sobre la estilística}

La estilística de Dámaso Alonso tomó como punto de partida algunos de los postulados del estructuralismo de Ferdinand de Saussure. La cuestión capital residía en analizar de forma científica los textos, y, para hacerlo, se debía partir de una cualidad inherente al texto: la palabra. Así, Alonso "desplegó ya un interés científico por las particularidades lingüísticas de los textos literarios" (Tuset Mayoral, 2015: 65) y se unió así a gran parte de las corrientes de la época. Podemos pensar en Jakobson, quien también 
reformuló algunas de las ideas de Saussure, el genio ginebrino, o en la glosemática de Hejlmslev. La huella de tales padres se aprecia en algunas publicaciones ya clásicas, como la guía de análisis El comentario de textos, editado por Castalia, que reunía, en 1973, a gran parte de los estudiosos hispánicos, tanto de la lingüística como de la literatura, en un mismo afán: Emilio Alarcos, Manuel Alvar, Andrés Amorós, Carlos Bousoño, Elena Catena, Marina Mayoral, Gregorio Salvador, Gonzalo Sobejano, José Manuel Blecua... La mera citación de los nombres abruma.

No todos estos especialistas abordaron el análisis del texto desde el punto de vista lingüístico e idealista, pero muchos de ellos bebían de sus enseñanzas epistemológicas. Sin embargo, esta "sombra alargada" de la estilística pudo provocar un retroceso en las posibilidades de la teoría literaria o, al menos, eso es lo que algunos han señalado, como Vicente Tuset Mayoral, para quien la estilística alonsiana condicionó la recepción de las corrientes europeas de análisis del texto literario (2015: 69). La idea ha arraigado en las últimas décadas y a día de hoy los potenciales integrantes de una escuela estilística pueden llegar a renunciar a ella, por esa sensación de tapón metodológico frente a las novedades europeas. Incluso, sin siquiera tener real consciencia de que son herederos del método planteado por Dámaso Alonso. Quizás la sorprendente explicación de este fenómeno de omisión resida en la propia naturaleza ecléctica de la estilística propuesta por Alonso.

Sin embargo, según se desprende de Tuset Mayoral o de Ruíz Pérez (1996), la estilística tuvo una fortuna "inmerecida”. Estos autores ven como un demérito que el método de Alonso supiese adaptarse a lo ficticio, a la naturaleza del constructo, lejos de pretender sistematizar el campo de lo surgido de la imaginación, como se percibe en parte de la crítica estructuralista. La estilística supo que la única forma de lograr un análisis era constituir una hermenéutica del espíritu, sirviéndose de lo material -el famoso signo de Saussure- "para dar cuenta de significaciones que ya están realizadas: la obra literaria” (Tuset Mayoral, 2015: 69). La crítica, por tanto, reside en que Alonso realizaba una "soldadura del sentido" que partía de un cientificismo que reconocía que el análisis de un texto dependería del alma que este atesorase, merced 
a una diferenciación entre lengua común y lengua poética. O lo que es lo mismo, que a partir de "una vinculación motivada entre significante y significado" (Alonso, 1950: 31-32) se podía inferir el estilo, tono e intención de un autor: "La estilística analiza el lenguaje ya configurado en una obra literaria, que tiene un indudable valor social, pero no le interesa tanto esta dimensión como los indicios que lo convierten en algo individuante, en la lengua específica de un autor" (Tuset Mayoral, 2015: 72).

Idealismo puro y duro, del que Alonso no reniega, y desde el que se infiere que debido a la "unicidad" de un texto resulta difícil conocer la plenitud del mensaje literario, tan solo intuirlo, pues intervienen otros factores de índole conceptual ya que el significante "moviliza innumerables notas del entramado psíquico" (1950: 23) del receptor. No obstante, el análisis será más interesante cuanto mejor preparado esté el estudioso, y cuando reconozca un primer nivel de conocimiento que radica en el sistema lingüístico. Cada signo se basa en el arbitrio de una relación entre el significante y el significado, aunque en un texto literario exista una vinculación motivada. Y estas relaciones, en la literatura, son el secreto. O, como decía en sus críticas Ruíz Pérez, su inmanencia, porque:

[...] de su formalización procede la estructuración artística del texto y en ella se sustenta su permanencia, al tiempo que constituye el elemento más inequívocamente textual y, por tanto, más objetivable y susceptible de ser analizado de manera inmanente, aislando todo lo extratextual. (1996: 565)

Así, la estilística pone en el foco la disposición lingüística, que parte de la voluntad del autor. Por lo que la clave en el análisis estilístico acaba siendo la indagación de esa voluntad. ¿Es esto posible? Tal vez, hubiera que tomar el concepto de "forma interior" y "forma exterior" que propone Alonso: “[...] Dámaso diferencia una forma exterior, en la que significante y significado se relacionan en la perspectiva desde el primero hacia el segundo, de una forma interior, con la perspectiva inversa, desde el significado al significante" (Marcos Marín, 2005). Y deslindarlo en dos: una forma del autor y una forma del lector. Es aquí donde aparece el 
reconocimiento moderno que, quizás, la estilística alonsiana no terminaba de reconocer. La disposición de las palabras, el estilo, define al autor, como indicó Ruíz Pérez citando a Georges-Louis Leclerc, Conde de Buffon (1996: 568), pero también define la recepción de la palabra.

\section{3.}

\section{Jesús Montiel: una aplicación}

Conviene ahondar en el método estilístico con un ejemplo. Dámaso Alonso dio cuerpo a su teoría con el análisis de poetas como Garcilaso o Góngora. En este capítulo, dentro de las nuevas hornadas de la poesía española, se destaca el nombre de Jesús Montiel López (Granada, 1984), premio Hiperión de Poesía 2016 por Memoria del pájaro, cuyo afán poético va más allá de la mera constatación de lo real y busca sumergirse en los misterios de lo oculto. Realmente, con esta descripción parece un autor susceptible de ser analizado mediante el idealismo alonsiano.

Montiel parte de la experiencia para escribir algunos de sus poemarios, como Placer adámico (2012) o Díptico otonal (2012), en los que aúna la presencia del dolor con la felicidad, por lo general bajo un prisma cristiano. Su lenguaje poético abarca un objeto exterior a él, la realidad misma, pues en muchos de sus poemas Montiel inserta experiencias de su propia vida, como los detalles de la leucemia que tuvo uno de sus hijos:

Pienso mucho en tu próxima tarta, la de los cuatro años. Casi puedo ver sus cuatro llamas perplejas, dudando tu canción de cumpleaños.

Sólo los niños, los tontos, los santos y los locos lográis vivir sin asomaros al futuro. (Montiel, 2018: 38)

Curiosamente, esto le pone en correlación con el propio método estilístico, pues este contempla como base de la construcción literaria la expresión lingüística -que sería el objeto exterior a la 
realidad-. Además, Montiel es ideal para renovar la estilística, pues es cierto que en ocasiones los epígonos alonsianos cayeron en el error de un radicalismo idealista, manifestado en la idea de que el lenguaje poético, al ser una construcción de la voluntad de un autor, buscaba con desesperación el retoricismo. En ese sentido, algunas de las afirmaciones de Ruíz Pérez, en cuanto al valor funcional y comunicativo de la palabra, permiten que la estilística se asiente en la doble forma, en la del autor y la del lector, hasta el punto de constituir unos "valores de singularidad, junto con los del yo y el sentimiento, fundidos en la noción de expresividad, que se convierten en los dominantes, hasta el punto de determinar con su aparición la poeticidad de lenguaje" (Ruíz Pérez, 1996: 581). Montiel, en estos poemarios, se caracteriza por un cuidado de la palabra poética, pero no cae en lo artificioso, al intentar captar la existencia que ya está presente per se en la realidad, antes de adentrarse en los vericuetos de la esencia. Así, en este sentido, un poema interesante sería "Nocturno", de Placer adámico:

¿Qué misteriosa ley ha permitido

a los ojos del hombre habituarse

a noches como ésta con sus astros

vibrando sobre el mapa y nuestras vidas?

Es extraño tener que recordarme

la dicha de estar vivo para no

desatender el don de la presencia.

En un instante así como el de ahora,

obligarme a salir

del santuario gris de la costumbre

para asomar el corazón sediento

a este paisaje negro y reanimarlo

con la copla del grillo.

Entonces me estremece un sentimiento

poderoso de chocante gratitud,

como si el mundo fuera una gran fiesta

a la que todos somos invitados

y su anfitrión un Dios que nos seduce.

(Montiel, 2012: 17) 
El poema nos recuerda al marco existencialista de los años 50, aunque con un irresistible poso optimista. En el poema ya se percibe la idea que transitará por toda la obra de Montiel hasta el conjunto de prosas poéticas Sucederá la flor (2018) como indica Asencio Navarro:

[...] la constatación de que la vida desobedece y camina indiferente a nuestras exigencias. Nada de lo que aparece en él es noticiable. Todo es pequeño y aparentemente insignificante. Es su mirada la que ilumina los rincones de la realidad y la que halla asideros en las grietas del dolor (Asencio Navarro, 2018).

En "Nocturno", el tono que presenta Montiel es un tono lleno de asombro, un asombro ante la existencia que se complace en suscitar la evocación que se encuentra oculta dentro de la memoria de cualquier lector. Visto así, versos como "Es extraño tener que recordarme / la dicha de estar vivo para no / desatender el don de la presencia" resuenan con plenitud gracias al uso de aliteraciones en $/ \mathrm{r} / \mathrm{y} / \mathrm{n} /$, una fuerza que muestra en la forma del lector, es decir, en su lectura, el asombro que hay por el sentimiento que aparece en el yo lírico al verse invitado a la fiesta de la vida. Esto se corresponde con la propia forma del autor, con la intención de sentido en la creación, con la forma externa alonsia$n a$, que se potencia con la elección de palabras, una red isotópica marcada por la paradoja en estos adjetivos: extraño, misterio$s a$, chocante y por una extraña felicidad que desborda el poema a través de otras elecciones léxicas: vibrando, dicha, santuario... El asombro del lector se conecta así con el asombro que el propio autor siente al hablar de la existencia. Esto se relaciona con algunas confesiones que Montiel ha hecho en algunas entrevistas muy recientes:

Yo me considero cristiano, pero cuando estoy con cristianos, me dicen que soy muy heterodoxo y cuando estoy con gente atea, me dicen que soy muy ortodoxo. Entonces, como dice Pablo d'Ors, me siento en la frontera. Tengo muchas contradicciones y siempre que me dicen blanco veo el negro, y cuando me dicen 
negro, veo el blanco. Pero la fe está muy presente en mi vida y en la forma de encarar la realidad (Asencio Navarro, 2017).

Esto revela que la contradicción late en él. La tradición existencial en lengua española, representada en autores como Unamuno, Blas de Otero o el propio Dámaso, pasa también por Montiel, pero su expresión es diferente. El estilo y el tono descubren a un poeta vitalista, que, sorprendentemente, conecta desde un punto de vista biológico-cultural con la filosofía de Ortega, quien tiende a ver la vida como un impulso natural, como pura vivencia. Sin embargo, en Montiel están muy presentes las ideas cristianas, aunque coquetea con cierto panteísmo. Esto se escenificará mejor en cuanto a una poética de lo pequeño, que sabe que, tras el dolor de la vida, hay que tener optimismo por cualquier hecho, por nimio que sea. De ahí que en el poema "Laberinto", tras un comienzo pesimista en el poeta, que desearía ser mucho más estoico y mucho menos observador, acabe diciendo:

Tal vez será mejor

buscar entre los muros un refugio,

zanjar la exploración de una abertura,

cavar un domicilio entre las flechas

que yerran diariamente tus pisadas.

Escribir, por ejemplo,

y que el poema sea ese descanso

en donde el hombre

-herido por la luz de cada cosa-

ya nunca más indague.

(Temblor, 2017)

Así, el alma solo podrá ser en su totalidad en un mundo que supere los lastres de la experiencia material. El alma será a través del descanso, a través del regocijo, incluso con el sufrimiento de la descendencia. La forma interior se erige por fin en forma externa, y las palabras marcan el estilo y sentido del poema: flechas, luz, poema, descanso... que acaban recordándonos a otra de las inspiraciones de Montiel, Amalia Bautista, cuando en el poema "Al cabo" dice: 
Al cabo, son poquísimas las cosas

que de verdad importan en la vida:

poder querer a alguien, que nos quieran

y no morir después que nuestros hijos (2006: 99).

Finalmente, al analizar estos pocos ejemplos de Montiel y de sus maestros literarios, el lector observa, tras ahondar en su palabra, cómo con cualquiera de las formas de análisis, la vida se impone como algo inefable e indestructible, algo por lo que se pregunta el poeta ante la sucesión de momentos y estampas que llega a contemplar. La vida se manifiesta por tanto en los hechos menos singulares y sorprendentes, en la naturaleza. Montiel habla del laberinto, de la noche, de la tarta de cumpleaños dudosa, al igual que el francés Christian Bobin, otra de sus inspiraciones, que dice en Autorretrato con radiador (1997) que hablará de las peripecias de una flor de cerezo. El tema existencial late en estos autores con un tono unánime, con una forma externa distinta, pero concluyente. Sus palabras se llenan de la música de lo común, ya que, en palabras de Montiel, el poema ha de hablar del "dolor dentro de la vida" (Asencio Navarro, 2017) y "la memoria guarda las emociones estéticas" (Asencio Navarro, 2017) para mostrar la alegría eterna del vivir, de lo nimio, de lo pequeño.

\section{4. \\ Conclusión}

En conclusión, la estilística nos enseña que la naturaleza de la poesía no es la mera unión de palabras más o menos evocadoras, aunque el basamento de su análisis sea la lengua. La estilística trata de mostrar al estudioso cómo el hecho poético se fundamenta en unidades semántico-sintácticas que realzan su valor en dos fases, en dos formas. La forma externa, la forma interior, la mirada del autor, la mirada del lector. La clave, no obstante, está en el misterio, en la elección de la palabra adecuada. Los ejemplos anteriormente expuestos pertenecientes a la obra poética de Jesús Montiel 
dan cuenta de ello: van más allá de la unión del significante y su significado gracias a la creación de un sentido que trasciende las previsiones de código. La concepción poética de la que hace gala Montiel en estos casos concretos radica en la unión entre la sugestión sonora y el uso de la palabra exacta, el uso del lenguaje como expresión estética de la conciencia del hombre, de ahí que sus procedimientos estilísticos (encabalgamientos, aliteraciones, incluso el anti-retoricismo, etc.) respondan a una poesía que va más allá de la forma. Una forma que mediante los principios de la construcción sintáctica abraza una referencia creada por el repertorio paradigmático, es decir, el de los signos presentes y no presentes. En un caso, la mirada del autor, del autor en la noche al lado de su hijo enfermo; en el otro, la mirada del lector, que crea nuevos tipos de contigüidad, es decir, de valores paradigmáticos, los cuales radican en su experiencia subjetiva.

Así, Jesús Montiel es consciente de ello y se afana en nombrar la vida, porque a través de las pequeñas cosas se da la superación de lo efímero. De ahí que el poeta renuncie a un grito exagerado y desgarrador, propio de existencialismos de otras épocas. La estilística, y con esto terminamos, es el método que se ha elegido para ahondar en este rasgo suyo, pese a que no sería la única manera de conocer la poética de Montiel. Pero, desde luego, es un buen instrumento de análisis, que conviene recuperar, pues subordina cualquier pretensión de exacerbada sistematización a la naturaleza poética del arte, porque, como el propio Jesús Montiel, el experto literario puede, a través de su metodología, conocer lo incognoscible de la palabra, su dimensión sacra que hace, más que nunca, que se le pueda denominar verbo o emoción.

\section{Bibliografía}

Alonso, D. (1950). Poesía española: ensayo de métodos y límites estilísticos. Madrid: Gredos.

Asencio Navarro, R. (2017). “Jesús Montiel: la literatura es una puerta estrecha y atravesarla consiste en estar solo, en el escritorio", [en línea] <https://temblorpoesia.com/entrevista-jesus-montiel> [7.11.2018]. 
Asencio Navarro, R. (2018). La vida desobediente de Jesús Montiel, [en línea] <https://temblorpoesia.com/1434-2> [7.12.2018].

Bautista, A. (2006). Tres deseos [Poesía reunida]. Madrid: Renacimiento.

Marcos Marín, F. (2005). "Pluralidad del español en los Estados Unidos de América”, en C.A. Molina (coord.). El Español en el Mundo: anuario del Instituto Cervantes, 283-358.

Montiel, J. (2012). Placer adámico. Madrid: Universidad Complutense.

Montiel, J. (2018). Sucederá la flor. Madrid: Pretextos.

Ruíz Pérez, P. (1996), "El lenguaje poético después de la estilística. Cuestiones de historia y materia", Revista de Filología y su didáctica, 18-19, 563-597.

Temblor - Asidero Poético (2017). “Tres poemas de Jesús Montiel, más un inédito", [en línea] <https://temblorpoesia.com/ tres-poemas-de-jesus-montiel-mas-un-inedito $>$ [7.11.2018].

Tuset Mayoral, V. (2015). "Herencia estilística y voluntad de renovación en la crítica literaria española de los setenta. Algo sobre Dámaso Alonso, Carmen Bobes Naves y Antonio García Berrio", $452^{\circ} \mathrm{F}, 12,63-82$. 